\title{
Compositional dependence of structure and wetting properties of CoO-doped silicate glass for porcelain enamel
}

\author{
Jaemin CHA ${ }^{1}$, Jaeyoung SHIN ${ }^{2}$, Junhyeon BAE ${ }^{2}$, Daegeol JEONG ${ }^{2}$ and Bongki RYU ${ }^{2, \dagger}$ \\ ${ }^{1}$ The Institute of Materials Technology, Pusan National University, Busan 46241, Korea \\ ${ }^{2}$ Division of Materials Science and Engineering, Pusan National University, Busan 46241, Korea
}

\begin{abstract}
In this study, we investigated the relationship between the structural changes and wetting properties of porcelain enamel doped with $\mathrm{CoO}$. Glass with the composition $45 \mathrm{SiO}_{2}-15 \mathrm{~B}_{2} \mathrm{O}_{5}-25 \mathrm{NaO}-15 \mathrm{CaO}$ was doped with different $\mathrm{CoO}$ concentrations. The wetting properties were characterized by high-temperature microscopy and the structural changes were observed by scanning electron microscopy, X-ray photoelectron spectroscopy, electron probe microanalysis, Fourier transform infrared spectroscopy, and energy dispersive $\mathrm{X}$-ray spectroscopy. CoO addition increased the number of non-bridging oxygen atoms in the glass system, as well as the wetting ability. The addition of $\mathrm{CoO}$ to the porcelain enamel not only increased adherence, but also decreased the sintering temperature. (C2018 The Ceramic Society of Japan. All rights reserved.
\end{abstract}

Key-words : Enamel, Co-Fe, Wetting property, Structural Change

[Received February 14, 2018; Accepted March 27, 2018]

\section{Introduction}

Enamels are thin layers of glass on metal substrates. Many studies have investigated the adhesion of enamels to steel plates. Enamels are primarily used to coat metals such as gold, silver, and copper. ${ }^{1)}$ Enamel coatings commonly comprise two layers. The first layer adheres to the metal body and the second cover layer enhances the appearance of the piece and protects its properties. ${ }^{2), 3)}$ Recently, single-layer enameling has become more popular in the production of architectural parts and chemical reactors, gradually displacing two-layer enameling because of the decreased number of applications and firings required for fabrication. ${ }^{4), 5)}$ Therefore, single-layer enamels must be defect-free in order to provide simultaneous chemical durability and adhesion ability.

Many previous reports on this topic have described theoretical models of the adhesion between enamel and steel. In a mechanical model, a rough interface is required for strong adherence because it enables mechanical anchoring. The rough surface is obtained by chemical corrosion and dendrite growth upon firing. ${ }^{6)-8)}$ In a chemical model, direct atomic bonds must be formed in an intermediate oxide layer between the metallic bonds of the substrate metal and the ionic bonds of the enamel. ${ }^{9), 10)}$ $\mathrm{Ni},{ }^{11)} \mathrm{Co},{ }^{12), 13)}$ and $\mathrm{Ti}^{13)}$ are commonly used to improve adherence, but the doping of enamel with Co has been observed to be more effective than that with $\mathrm{Ni}$ or $\mathrm{Ti}^{1}{ }^{13), 14)}$

The aim of the present study is to investigate the effect of the addition of Co on the adherence property of single-

Corresponding author: B. Ryu; E-mail: bkryu@pusan.ac.kr layer enamel using high-temperature microscopy and on the enamel structural changes using scanning electron microscopy (SEM), X-ray photoelectron spectroscopy (XPS), electron probe microanalysis (EPMA), Fouriertransform infrared spectroscopy (FTIR), and energy dispersive X-ray spectroscopy (EDX).

\section{Experimental method}

The chemical composition of the enamel frit is $45 \mathrm{SiO}_{2}-$ $15 \mathrm{~B}_{2} \mathrm{O}_{3}-25 \mathrm{Na}_{2} \mathrm{O}-15 \mathrm{CaO}-x \mathrm{CoO}(x=0,2,4$, and $6 \mathrm{wt} \%)$. All materials were purchased from Junsei Chemical Co. (Tokyo, Japan) and batches were mixed by continuous grinding for homogenization. The mixed batches were melted at $1350^{\circ} \mathrm{C}$ for $1 \mathrm{~h}$. The molten glass was then quenched on a stainless steel plate. The obtained glasses were annealed at the glass transition temperature, $T_{\mathrm{g}}$, for $1 \mathrm{~h}$, cut, and mechanically polished to obtain samples for thermal analysis. The thermal properties of the glasses were investigated using a thermal mechanical analyzer (Q400, TA Instruments) in the range from room temperature to $610^{\circ} \mathrm{C}$ with the heating rate of $10^{\circ} \mathrm{C} / \mathrm{min}$. The thermal property values were determined for each glass using the associated computer software; the accuracy of the measurements was $\pm 2^{\circ} \mathrm{C}$, based on the average of three replicates.

The enamel frit was manufactured using a typical procedure after milling to 200 mesh. Sheets of steel (POSCO, Korea, $\mathrm{C}<0.08 \%$ ) were treated to remove all surface oils and rust for use as the enamel substrate. The all-enamel slip was manually coated on $10 \times 10 \mathrm{~cm}$ steel plates using a spray gun, creating layers with an average thickness of approximately $150 \mu \mathrm{m}$ (equal to $4-6 \mathrm{~g}$ ). The coated plates 
were dried at $200^{\circ} \mathrm{C}$ for $10 \mathrm{~min}$ and then fired in a box furnace at 800,850 , and $900^{\circ} \mathrm{C}$ for $10 \mathrm{~min}$.

To understand the microstructure of the enameled steels produced with different $\mathrm{CoO}$ amounts, cross-sectional specimens were prepared by a standard metallography procedure. The interfacial microstructure was examined using SEM (SUPRA40VP, ZEISS). The microscope was operated at an accelerating voltage of $20 \mathrm{kV}$. The elements in the glass/steel interface were chemically analyzed using an EDX system on the SEM. EPMA (SX100, Cameca) was employed to study the details of the interfacial reactions between the enamel coating and the steel substrate.

XPS was employed to analyze the changes in bridging and non-bridging oxygen atoms in the glass. XPS measurements were performed using ESCALAB250 XPS and Theta Probe XPS systems using monochromatic Al K $\alpha$ $(\mathrm{h} v=1486.6 \mathrm{eV})$ radiation conditions. The analysis area was $400 \mu \mathrm{m}$ and the data was compensated using $\mathrm{C} 1 \mathrm{~s}$ $(284.6 \mathrm{eV})$ as the reference. With a good signal-to-noise ratio, errors in the peak positions are $\pm 0.2 \mathrm{eV}$.

In order to observe partial structure changes, attenuated total reflectance (ATR) FTIR ATR-FTIR (Nicolet ${ }^{\mathrm{TM}}$ $\mathrm{iN}^{\mathrm{TM}} 10$ Infrared Microscope, Thermo Scientific) measurements of the samples were performed. A square aperture of $30 \times 30 \mu \mathrm{m}$ was set parallel to the enamel/substrate interface. The square aperture was moved from the glass to the substrate for measurement. A series of FTIR spectra were recorded with a resolution of $4 \mathrm{~cm}^{-1}$.

Contact angle measurements were performed on the glass samples using an automatic hot-stage microscope (HSM, H. Lab Co, Korea). The measurement was performed in air at the heating rate of $10^{\circ} \mathrm{C} / \mathrm{min}$. The samples for these measurements were made using a hand press to compress $0.1 \mathrm{~g}$ of the glass frits, which were placed within a small cylindrical metal mold $(10 \times 10 \mathrm{~mm})$. A sample image automatically recorded and analyzed the sample geometry during heating process. An alumina plate $(20 \times$ $20 \times 0.7 \mathrm{~mm}$ ) was used as the substrate.

\section{Results and discussion}

Figure 1 shows SEM images of the interface between the enamel and steel. In the case with no $\mathrm{CoO}$ in the enamel glass, the precipitation of the micro-alloy is lacking, which results in a smooth interface without dendrites [Fig. 1(a)], but the CoO-doped samples show dendritic structures [Figs. 1(b)-1(d)].

Dietzel $^{15)-18)}$ reported an electrochemical reaction of Co and $\mathrm{Fe}$ that promoted adherence. Herein, Fe dissolves locally and causes significant roughening. Because of the deposition of $\mathrm{Co}$ and the selective dissolution of $\mathrm{Fe}$, dendritelike structures were observed. King et al. ${ }^{18)}$ showed that the dissolution of the $\mathrm{Fe}$ oxide layer was enhanced in the presence of Co. After the dissolution of the oxide layer, Co in the enamel reacts with Fe. In particular, some of the ferrous $\mathrm{Fe}$ is assumed to undergo a disproportionation reaction yielding ferric and metallic Fe, respectively, and the latter alloys with the reduced Co metals. Thus, it is assumed that the overall reaction is as follows: ${ }^{19)}$

$$
\begin{aligned}
& \mathrm{Fe}^{0} \text { (steel) }+\mathrm{Co}^{2+} \text { (glass) } \\
& \quad \rightarrow \mathrm{Fe}^{2+} \text { (glass) }+\mathrm{Co}^{0} \text { (interface) } \\
& 5 \mathrm{Fe}^{2+}+\mathrm{Co}^{2+} \text { (glass) } \rightarrow \mathrm{Fe}-\mathrm{Co} \text { (interface) }+4 \mathrm{Fe}^{3+}
\end{aligned}
$$

Interfacial reactions among $\mathrm{Co}$, enamel, and steel produce many small islands on the steel substrate. From the SEM micrograph of Fig. 1, it can be seen that the islands are interconnected to form anchor points, thus increasing the roughness of the interface. Similar improvements of the adherence of the enamel to steel by mechanical interlocking have been reported by other investigators. ${ }^{20), 21)}$

In order to confirm the $\mathrm{Fe}-\mathrm{Co}$ composition, EPMA was used to investigate the distribution of $\mathrm{Fe}$ and $\mathrm{Co}$ at the enamel/steel interface. Figure 2 shows the EPMA elemental maps of $\mathrm{Fe}$ and $\mathrm{Co}$ across the interface after heating at 850 and $900^{\circ} \mathrm{C}$. As is shown in Fig. 2, an obvious $\mathrm{Fe}-\mathrm{Co}$ dendrite is formed at the interface between the steel and glass enamel.
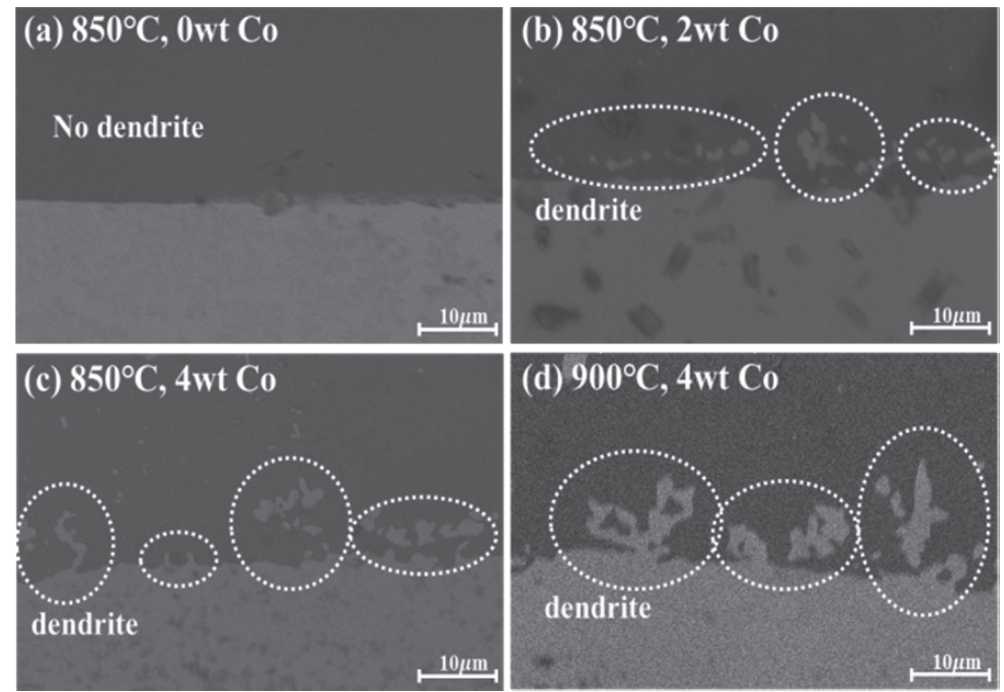

Fig. 1. SEM images of enamel/steel interface: (a) $0 \mathrm{wt} \% \mathrm{CoO}$ at $850^{\circ} \mathrm{C}$, (b) $2 \mathrm{wt} \% \mathrm{CoO}$ at $850^{\circ} \mathrm{C}$, (c) $4 \mathrm{wt} \%$ $\mathrm{CoO}$ at $850^{\circ} \mathrm{C}$, and (d) $4 \mathrm{wt} \% \mathrm{CoO}$ at $900^{\circ} \mathrm{C}$. Dotted circles indicate dendrite structures. 

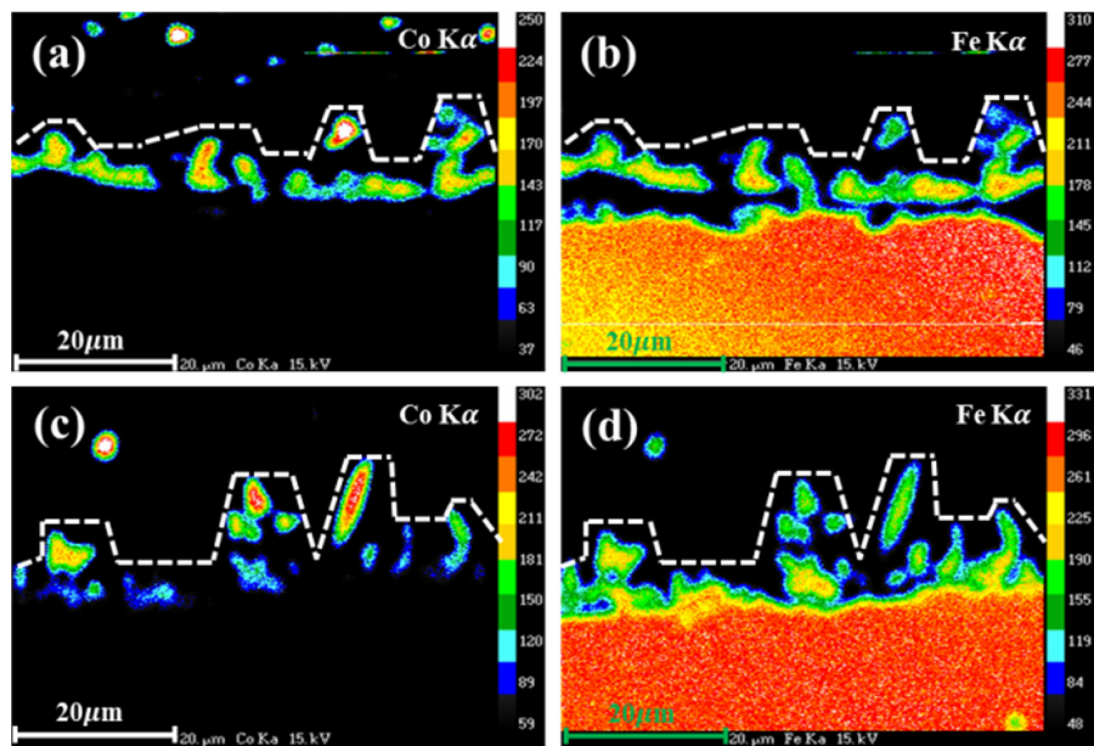

Fig. 2. EPMA image of interface between enamel and steel: (a) Co mapping of $4 \mathrm{wt} \% \mathrm{CoO}$ at $850^{\circ} \mathrm{C}$, (b) $\mathrm{Fe}$ mapping of $4 \mathrm{wt} \% \mathrm{CoO}$ at $850^{\circ} \mathrm{C}$, (c) Co mapping of $4 \mathrm{wt} \% \mathrm{CoO}$ at $900^{\circ} \mathrm{C}$, and (d) Fe mapping of $4 \mathrm{wt} \% \mathrm{CoO}$ at $900^{\circ} \mathrm{C}$.

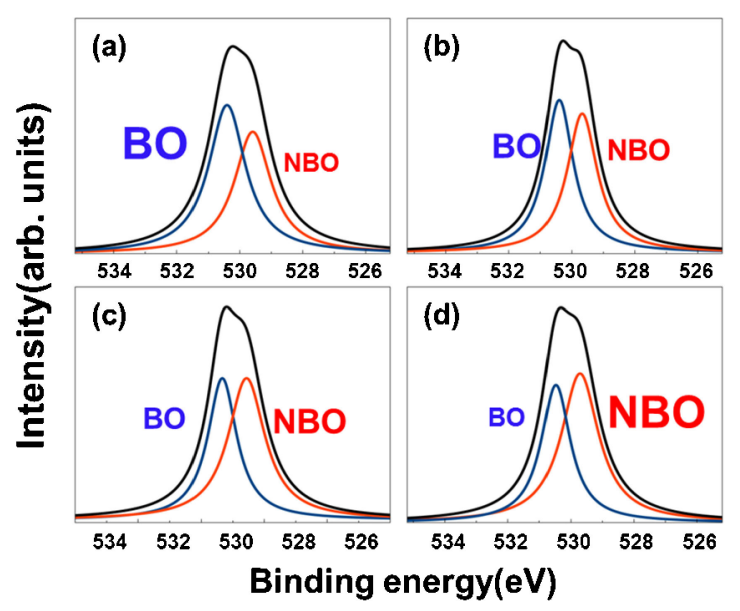

Fig. 3. High-resolution $\mathrm{O} 1 \mathrm{~s}$ core-level photoelectron spectra for (a) $0 \mathrm{wt} \% \mathrm{CoO}$, (b) $2 \mathrm{wt} \% \mathrm{CoO}$, (c) $4 \mathrm{wt} \% \mathrm{CoO}$, and (d) $6 \mathrm{wt} \% \mathrm{CoO}$.

Figure 3 shows the O $1 s$ core-level XPS peaks. The O $1 s$ spectra of the obtained glasses use Shirley backgrounds and Lorentzian-Gaussian line shapes. Based on O $1 s$ peak deconvolution with two contributions, the ratio between the number of non-bridging oxygen (NBO) and the total number of oxygen atoms was determined. The lower binding energy peak at $529.6 \pm 0.2 \mathrm{eV}$ is associated with NBO and the higher energy peak at $530.4 \pm 0.2 \mathrm{eV}$ with the bridging oxygen (BO). ${ }^{22)}$ The results of fitting the experimental $\mathrm{O} 1 s$ spectra show that the $\mathrm{BO} / \mathrm{NBO}$ ratio decreases as the Co content increases. ${ }^{23)}$ The $\mathrm{O} 1 s$ spectra are fitted with contributions from both $\mathrm{BO}$ and NBO; the NBO signal increases with increases in the $\mathrm{CoO}$ content, indicating that Co behaves as a network modifier.

Figure 4 shows the FTIR spectra of the base and Codoped glass heated at each temperature in the range of $700-1600 \mathrm{~cm}^{-1}$. As seen in the right-hand SEM image,
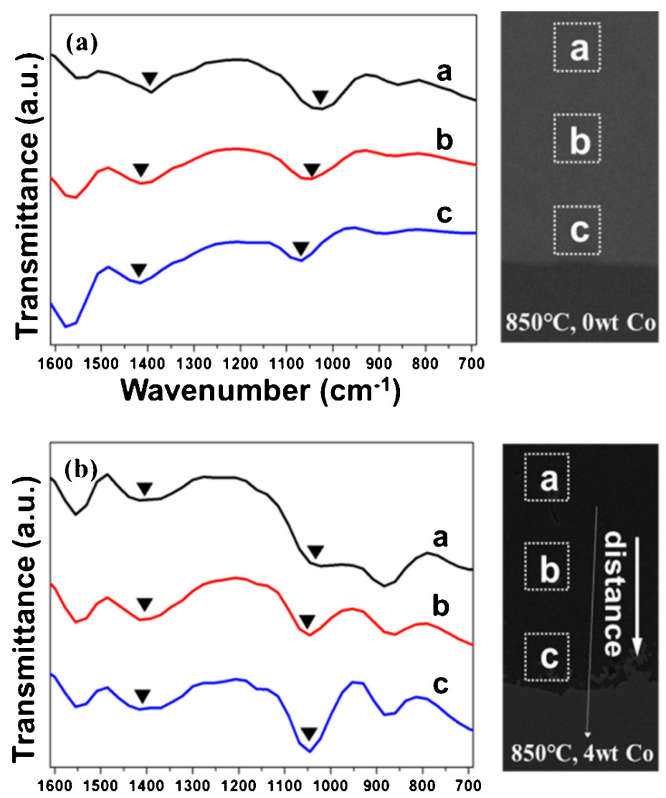

Wavenumber $\left(\mathrm{cm}^{-1}\right)$

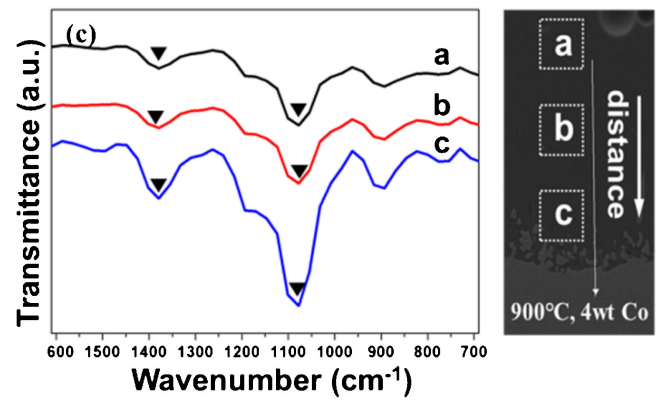

Fig. 4. FTIR spectra according to each position as a function of CoO contents: (a) $0 \mathrm{wt} \% \mathrm{CoO}$ at $850^{\circ} \mathrm{C}$, (b) $4 \mathrm{wt} \%$ at $850^{\circ} \mathrm{C}$, and (c) $4 \mathrm{wt} \%$ at $900^{\circ} \mathrm{C}$. 

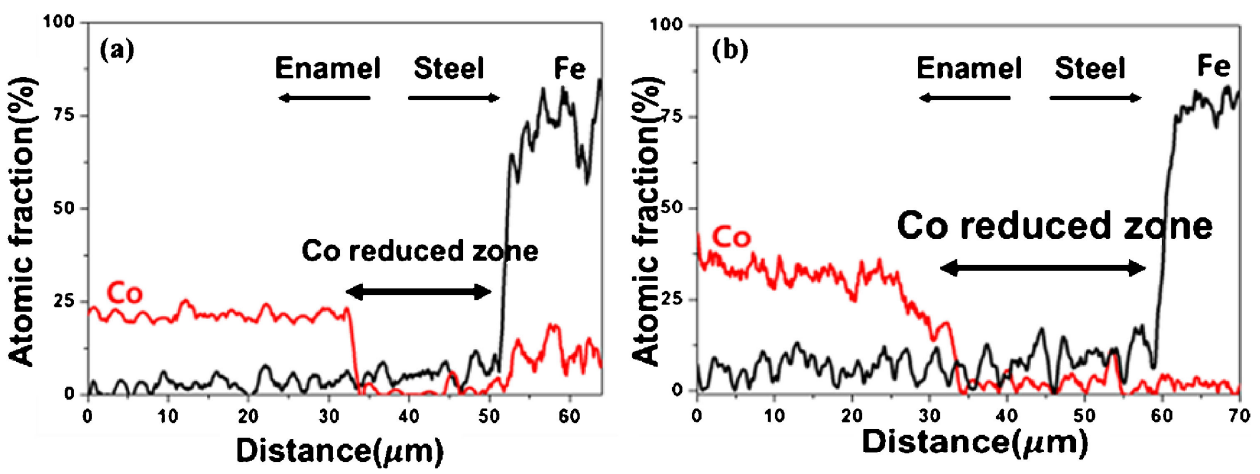

Fig. 5. Elemental distribution in cross-sections of enamel/steel plane of each specimen by EDX: (a) 4 wt $\%$ $\mathrm{CoO}$ at $850^{\circ} \mathrm{C}$ and (b) $4 \mathrm{wt} \%$ at $900^{\circ} \mathrm{C}$.

the measurement point (a) in the SEM image is far from the enamel/steel interface while (c) is near the interface. All the samples show similar trends; the FTIR spectral bands of all glasses confirm the main characteristics of the silicate network, possibly due to the presence of $\mathrm{SiO}_{2}$ as a major constituent. The major band at approximately 1028 $\mathrm{cm}^{-1}$ can be attributed to $\mathrm{Si}-\mathrm{O}-\mathrm{Si}$ stretching. The small band at $1400 \mathrm{~cm}^{-1}$ can be attributed to the $\mathrm{C}-\mathrm{O}$ vibration mode. The intensity of the peak is increased as the concentration of $\mathrm{CoO}$ increases, which is attributed to the breaking of the Si-O-Si network. ${ }^{24)}$ The intensity of the band increases with $\mathrm{CoO}$ addition to the base glass; therefore, the $\mathrm{CoO}$ increases the $\mathrm{NBO}$ in the network. Although differences in the $\mathrm{C}-\mathrm{O}$ peak at each measured point are not well observed from the $850^{\circ} \mathrm{C}$ sample in Fig. 4(b), the intensity of the $\mathrm{C}-\mathrm{O}$ peak is increased near the enamel/ steel interface in the $950^{\circ} \mathrm{C}$ sample in Fig. 4(c), which may arise from the $\mathrm{Co}-\mathrm{Fe}$ reaction depending on the temperature.

The temperature dependency of structural change also appears in the EDX results (Fig. 5). The EDX line scan across the interface shows that, with increasing temperature, the fraction of Co changes in the enamel. In the sample heat-treated at $900^{\circ} \mathrm{C}$, the decrease of Co is longer than that in the $850^{\circ} \mathrm{C}$ sample.

The effect of adding $\mathrm{CoO}$ on the thermal properties of the glasses is shown in Fig. 6. The thermal properties of the glasses are correlated with their compositions and structures. A monotonic change occurs in the glass transition temperature, $T_{\mathrm{g}}$, and the dilatometric softening temperature, $T_{\mathrm{d}}$. The $T_{\mathrm{g}}$ value decreases with increasing CoO, from 565.1 to $550.2^{\circ} \mathrm{C}$ as the $\mathrm{CoO}$ amount increases from 0 to $6 \mathrm{wt} \%$. The $T_{\mathrm{d}}$ value also decreases with increases in $\mathrm{CoO}$ from 0 to $6 \mathrm{wt} \%$, from 602.4 to $588.3^{\circ} \mathrm{C}$. Figure 6 also shows the effects of the Co amount on the coefficient of thermal expansion (CTE) of the glasses. The CTE of the glasses increases with increasing Co content, from $89.4 \times$ $10^{-7}$ to $92.4 \times 10^{-7} \mathrm{~K}^{-1}$. Therefore, the increase in CTE and the decrease in $T_{\mathrm{g}}$ and $T_{\mathrm{d}}$ with increasing Co content may be attributed to the increase in the NBO content. ${ }^{25}$ )

Good wettability is among the most important factors influencing favorable adhesion. The pellet shape of the glass with increasing $\mathrm{CoO}$ amount is depicted in Fig. 7;

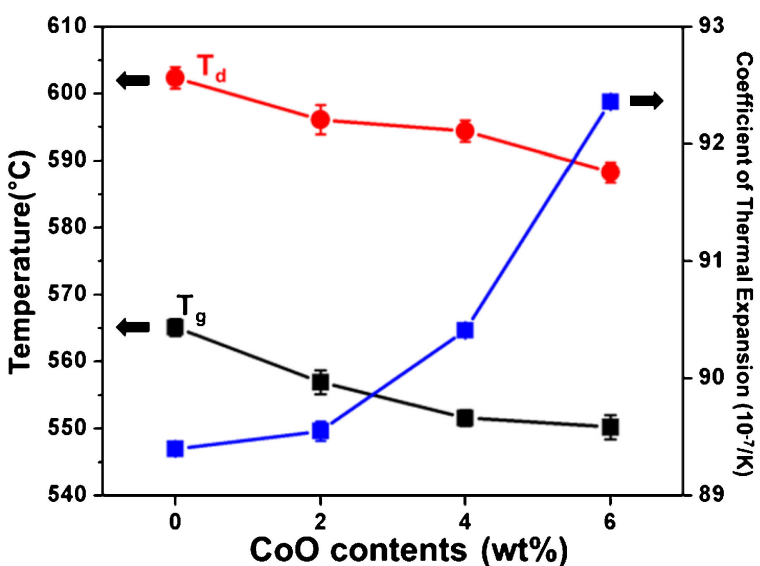

Fig. 6. Thermal properties of $\mathrm{CoO}$-doped glass as a function of $\mathrm{CoO}$ contents.

the pellets are initially cubic in shape (Region I). With increasing $\mathrm{CoO}$ amount, the pellet shape changes from cubic to spherical. The formation temperature of the swollen sphere is known as the softening point, $T_{\mathrm{s}}$. Heat energy first affects the corners because they have the largest surface area. Therefore, the corners of the pellet contract rapidly to reduce the surface energy. ${ }^{26)}$ At the higher temperatures $\left(>T_{\mathrm{s}}\right)$, the shape of the pellet changes to ellipsoidal (Region II) and the molten glass spreads over the substrate (Region III).

The wetting behaviors of the glasses on the low-carbon steel substrate were studied according to the $\mathrm{CoO}$ amount, as shown in Fig. 8. The wetting angle of the $0 \mathrm{wt} \% \mathrm{CoO}$ glass was maintained from room temperature to $750^{\circ} \mathrm{C}$. Above $750^{\circ} \mathrm{C}$, the glass begins to wet the substrate. As the amount of $\mathrm{CoO}$ increases, the starting temperature of the swollen sphere is decreased (Figs. 7 and 8). In this study, the wetting behaviors of the glasses containing $6 \mathrm{wt} \%$ $\mathrm{CoO}$ are better than that of the glass with $0 \mathrm{wt} \% \mathrm{CoO}$. Furthermore, the addition of higher amounts of $\mathrm{CoO}$ improves the wettability of the glass on the substrate at the same temperature. At $950^{\circ} \mathrm{C}$, the value of the wetting angle of the $6 \mathrm{wt} \% \mathrm{CoO}$ composition is approximately $62.8^{\circ}$. This phenomenon is closely related to the glass structure. As shown in the XPS and FTIR analyses, adding $\mathrm{CoO}$ changes $\mathrm{BO}$ into NBO. Consequently, the glass 


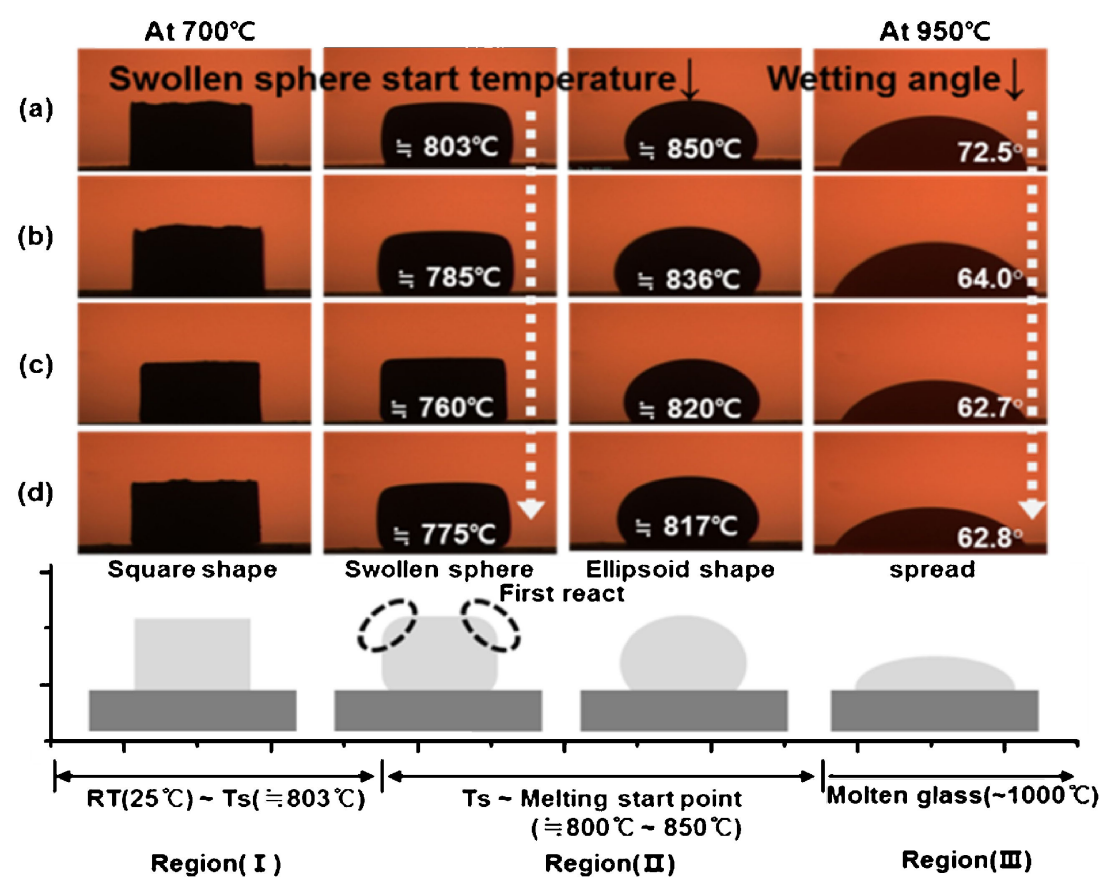

Fig. 7. Heat reaction of CoO-doped glass pellets on a substrate. (a) $0 \mathrm{wt} \% \mathrm{CoO}$, (b) $2 \mathrm{wt} \% \mathrm{CoO}$, (c) $4 \mathrm{wt} \%$ $\mathrm{CoO}$, and (d) $6 \mathrm{wt} \% \mathrm{CoO}$.

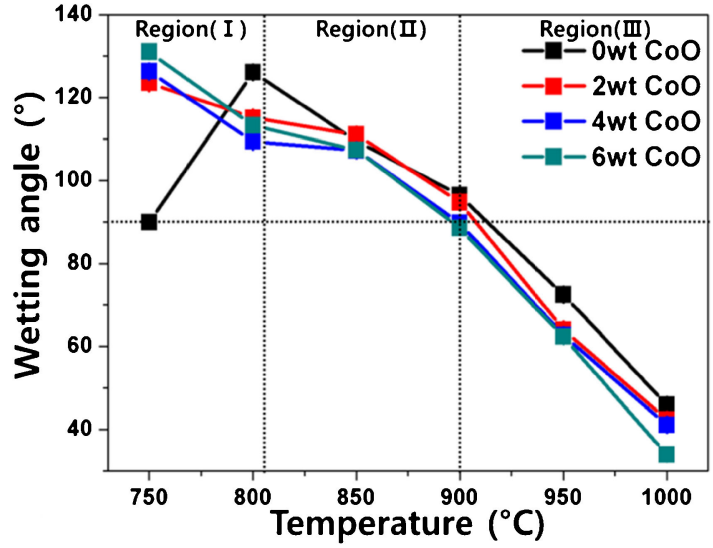

Fig. 8. Wetting angle of CoO-doped glasses as a function of temperature for various $\mathrm{CoO}$ contents.

network is weakened and the glass flows more easily, which improves the glass wettability.

\section{Conclusions}

In this study, the effects on the structure and wetting ability according to the amount of $\mathrm{CoO}$ in enamel were studied. $\mathrm{CoO}$ addition induces dendritic structures at the enamel/steel interface and improves the adherence of the enamel to steel by mechanical interlocking.

Regarding the structural changes, $\mathrm{CoO}$ functioned as a network modifier, increasing the amount of $\mathrm{NBO}$ as $\mathrm{CoO}$ was added to the glass structure. The thermal properties such as $T_{\mathrm{g}}$ and $T_{\mathrm{d}}$ are related to the glass structure; these characteristic temperatures were also decreased with increasing $\mathrm{CoO}$ amounts in the glasses.
Adding $\mathrm{CoO}$ increased the wetting ability of the enamel. The glass with $6 \mathrm{wt} \% \mathrm{CoO}$ shows the best wetting ability among the samples, with the wetting angle of $62.8^{\circ}$.

Acknowledgement This work was supported by the Korea Institute of Energy Technology Evaluation and Planning (KETEP) and the Ministry of Trade, Industry \& Energy (MOTIE) of the Republic of Korea.

\section{References}

1) D. M. Judd, Proceedings of the 59th Porcelain Enamel Institute Technical Forum, 18, 45-51 (2008).

2) S. Rossi, Z. Caterina and S. Ryan, Mater. Des., 55, 880 887 (2014).

3) I. G. Berdzenishvili, Am. J. Mater. Sci., 6, 45-48 (2016).

4) L. G. Protasova, V. G. Kosenko and E. P. Farafontova, Glass Ceram., 60, 229-230 (2003).

5) O. V. Shalygina, L. L. Bragina, G. I. Mironova and A. P. Odintsova, Glass Ceram., 71, 217-221 (2014).

6) D. Ritchie, H. A. Schaeffer and D. White, J. Mater. Sci., 18, 599-604 (1983).

7) D. Fick, C. Layne, D. Gnizak and H. Evele, 63rd Porcelain Enamel Inst. Tech. Forum: Ceram. Eng. Sci. Proc., 22, 107-114 (2001).

8) F. S. Shieu, M. J. Deng, K. C. Lin and J. C. Wong, J. Mater. Sci., 34, 5265-5272 (1999).

9) M. Bodaghi and A. Davarpanah, Proc. Appl. Ceram., 5, 215-222 (2011).

10) H. H. Liu, Y. Shueh, F. S. Yang and P. Shen, Mat. Sci. Eng. A-Struct., 149, 217-224 (1992).

11) E. A. Yatsenko, A. P. Zubekhin and E. B. Klimenko, Glass Ceram., 61, 90-93 (2004).

12) M. Shirasaki, T. Shimizu, T. Kozuka and Z. H. Jiang, J. Ceram. Soc. Jpn., 107, 222-228 (1999). 
13) T. Shimizu, Z. H. Jiang, M. Shirasaki and T. Kozuka, J. Ceram. Soc. Jpn., 106, 144-149 (1998).

14) F. S. Shieu, L. Lin and J. C. Wong, Ceram. Int., 25, 2734 (1999).

15) A. Dietzel, Emailwaren Ind., 11, 161-166 (1934).

16) A. Dietzel, Sprechsaal, 68, 3-6 (1935).

17) A. Dietzel, Sprechsaal, 78, 8-9 (1945).

18) B. W. King, H. P. Tripp and W. H. Duckworth, J. Am. Ceram. Soc., 42, 504-525 (1959).

19) J. Wendel, Proceedings of the 20th International Enamellers Institute Congress, May. 15-19, Istanbul, Turkey (2005).

20) J. C. Richmond, D. G. Moore, H. B. Kirkpatrick and W. N. Harrison, J. Am. Ceram. Soc., 36, 410-416
(1953).

21) A. G. Eubanks and D. G. Moore, J. Am. Ceram. Soc., 38, 226-230 (1955).

22) A. Mekki and M. Salim, J. Electron Spectrosc., 101103, 227-232 (1999).

23) A. Mekki, D. Holland, K. Ziq and C. F. McConville, J. Non-Cryst. Solids, 220, 267-279 (1997).

24) V. K. Vyas, S. K. Kumar, S. Prasad, S. P. Singh and R. Pyare, Bull. Mater. Sci., 38, 957-964 (2015).

25) H. Lee, C. Lee, J. Hwang and W. Chung, J. Korean Ceram. Soc., 54, 400-405 (2017).

26) S. Shim, D. Kim, S. Hwang and H. Kim, Thermochim. Acta, 496, 93-96 (2009). 